\title{
A CASE REPORT OF MULTIPLE ARTERIAL ANOMALIES IN A CADAVER
}

\author{
T. L. Anbumani ${ }^{1}$, A. Thamarai Selvi², S. Anthony Ammal ${ }^{3}$
}

\section{HOW TO CITE THIS ARTICLE:}

T. L. Anbumani, A. Thamarai Selvi, S. Anthony Ammal. "A Case Report of Multiple Arterial Anomalies in a Cadaver". Journal of Evolution of Medical and Dental Sciences 2015; Vol. 4, Issue 21, March 12; Page: 37243730, DOI: $10.14260 /$ jemds/2015/536

ABSTRACT: During routine dissection in our department, multiple arterial variations were observed in a cadaver. The following arterial variations are present. They are, superficial brachioulnar artery, which originated at the level of junction of upper and middle third of arm. It runs a superficial course anterior to median nerve in the arm and terminates in the formation of superficial palmar arch. The brachial artery terminated as radial and common interosseous artery. Subscapular artery and circumflex humeral artery arose as a common trunk from the third part of axillary artery. The circumflex humeral artery later divides into anterior circumflex humeral and posterior circumflex humeral arteries. The right common carotid artery bifurcated into internal carotid artery anteromedially and external carotid artery posterolaterally at the level of upper lamina of thyroid cartilage. A proper knowledge of variations in the arterial pattern is a must for a good treatment outcome, especially in the fields like vascular surgery, reconstructive surgery, cardiac surgery, angiogram, arterial cannulation, arterio-venous fistula for renal dialysis. etc.

KEYWORDS: Axillary artery, superficial brachioulnar artery, external carotid artery.

INTRODUCTION: Arterial variations are common manifestations. Variations in the branching pattern of upper limb arteries occur upto 20\% of the population. (McCormack et al. 1953; Wankoff, 1962; Rodriguez-Niedenfuhr et al. 2001). Awareness about these variations is necessary for a good treatment outcome and to avoid surgical complications.

This report describes concomitant presence of arterial variations in the upper limb and a unilateral variation of right external carotid artery. Clinical significance about these variations is also described in this case report.

MATERIALS, METHODS \& RESULTS: During routine dissection in our Department of anatomy at Karpaga Vinayaga Institute of Medical Sciences, Maduranthagam, the following arterial variations are observed in a single cadaver.

Bilateral superficial Brachioulnar Artery: It arises from the brachial artery at a point, $12 \mathrm{~cm}$ from the acromion process in the arm. It runs a superficial course in the arm and forearm, passes superficial to the flexor retinaculam and terminates by forming the superficial palmar arch along with the superficial palmar branch of radial artery. [FIGURE 1A, 1B, 2] 


\section{CASE REPORT}

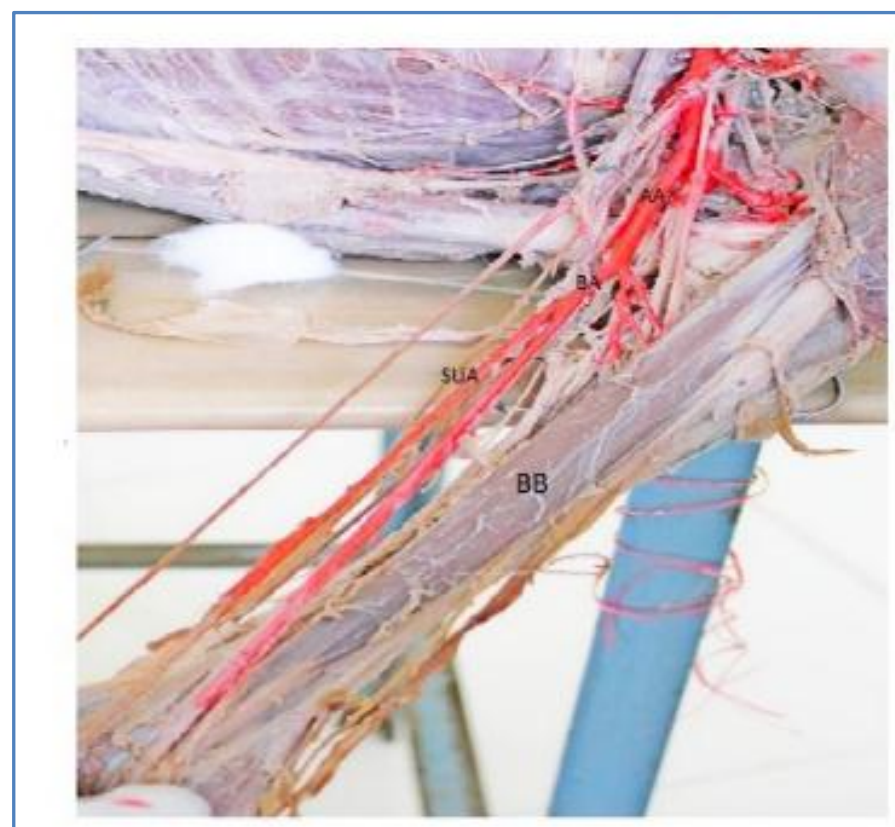

FIGURE 1A: Left Upper Limb: AA- axillary artery; BA- Brachial artery; SUA-superficial brachioulnar artery; BB-biceps brachil muscle

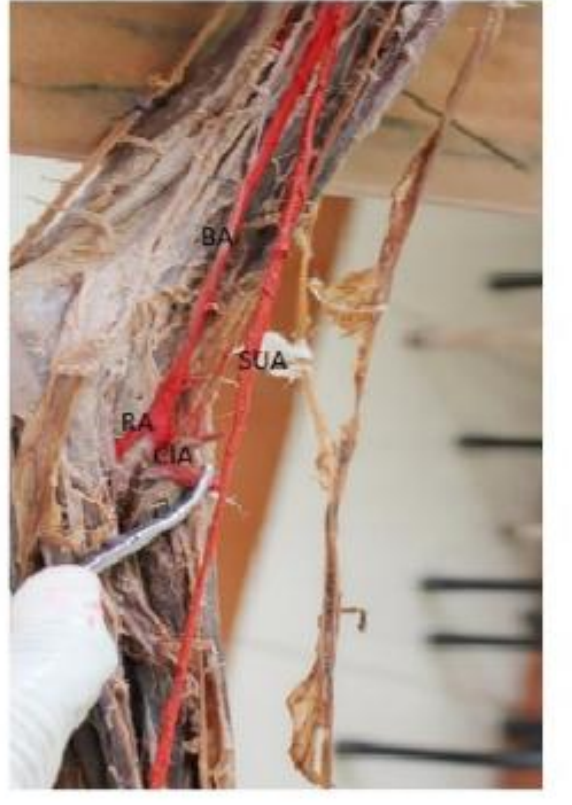

FIGURE 1B: Right Upper Limb; BA-Brachial Artery; SUAsuperficial brachioulnar artery; RA- radial artery; CIAcommon interosseous artery 


\section{CASE REPORT}

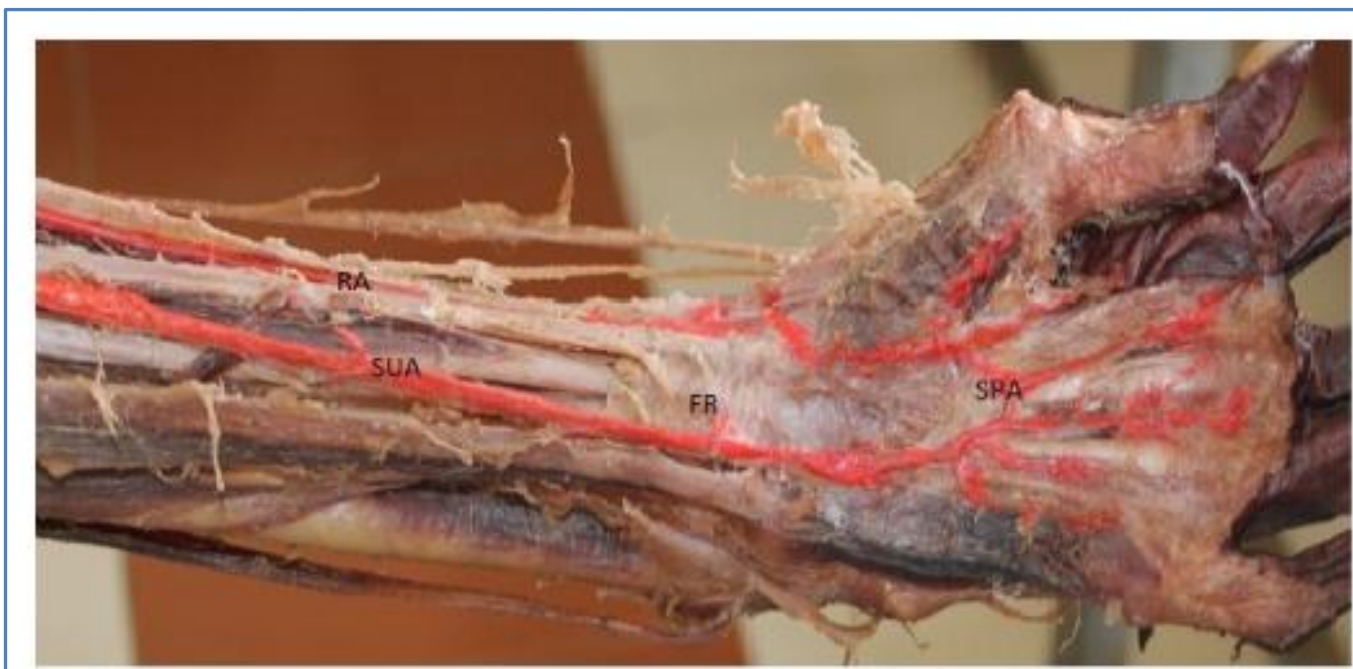

FIGURE 2: Left Upper LImb: RA- radial artery; SUA-superficial brachioulnar artery; FR- flexor retinaculam; SPA- superficial palmar arch

The brachial artery after crossing the elbow joint bifurcates into radial artery and common interosseous artery at the level of neck of radius bilaterally [FIGURE 3]. The common interosseous artery terminates by dividing into two branches namely anterior interosseous and posterior interosseous arteries.

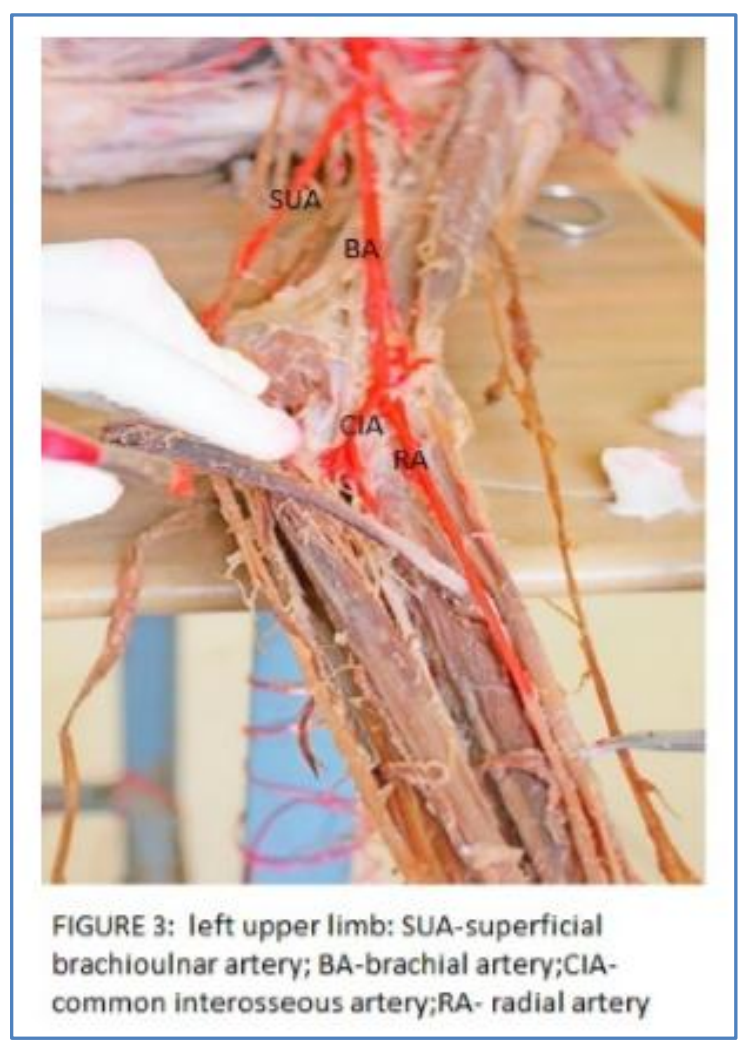




\section{Other arterial variations noted in the same cadaver are:}

- In normal course the third part of axillary artery gives rise to subscapular artery, anterior circumflex humeral and posterior circumflex humeral arteries.

- Whereas in this present case, on the left side, the third part of axillary artery gives rise to a common trunk, this divides into subscapular artery and cirumflex humeral artery [FIGURE 4A]. The cirumflex humeral artery further divides into an anterior and posterior circumflex humeral artery [FIGURE 4B].

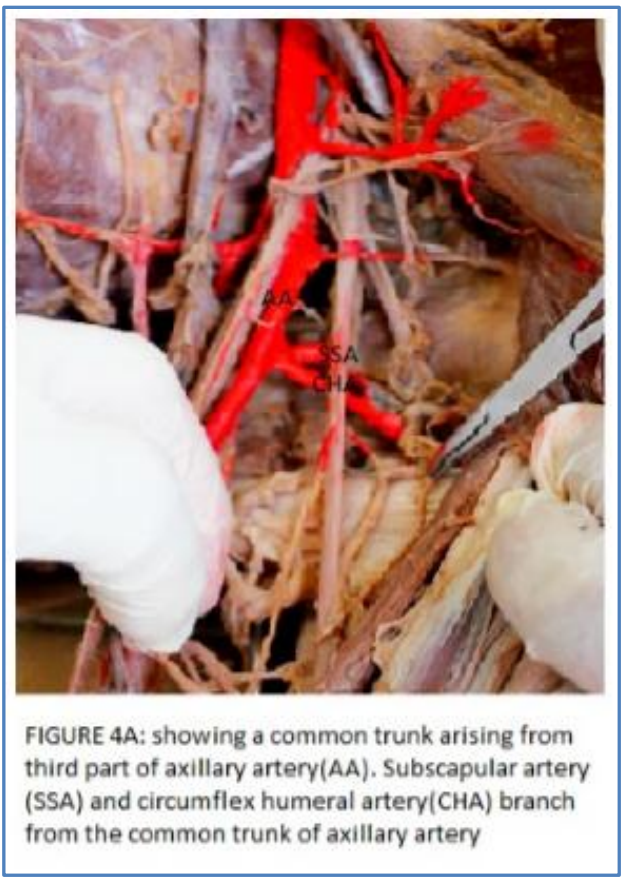

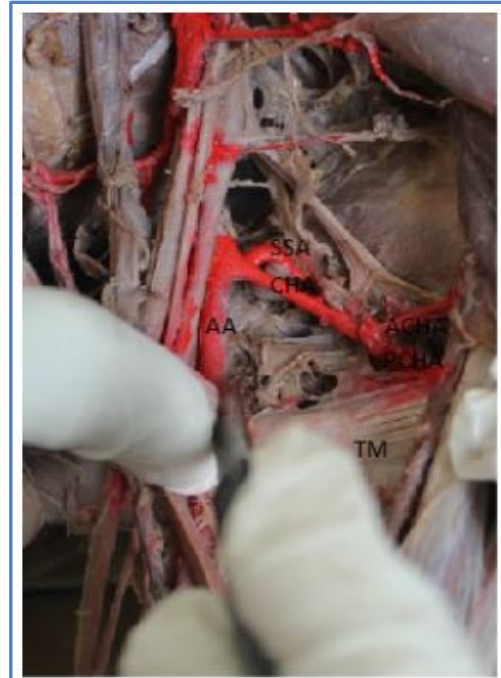

FIGURE 4B: Left axillary artery (AA); SSAsubscapular artery; CHA-circumflex humeral artery; ACHA-anterior cirumflex humeral artery; PCHA-posterior cirumflex humeral artery; TM-teres major muscle

- Normally the common carotid artery bifurcates into an external carotid artery and internal carotid artery at the level of upper lamina of thyroid cartilage. The external carotid artery is anteromedial to internal carotid artery.

- In this present case, the right common carotid artery bifurcates into internal carotid and external carotid arteries at the level of upper lamina of thyroid cartilage, the internal carotid artery being anteromedial to the external carotid artery [FIGURE 5A, 5B].

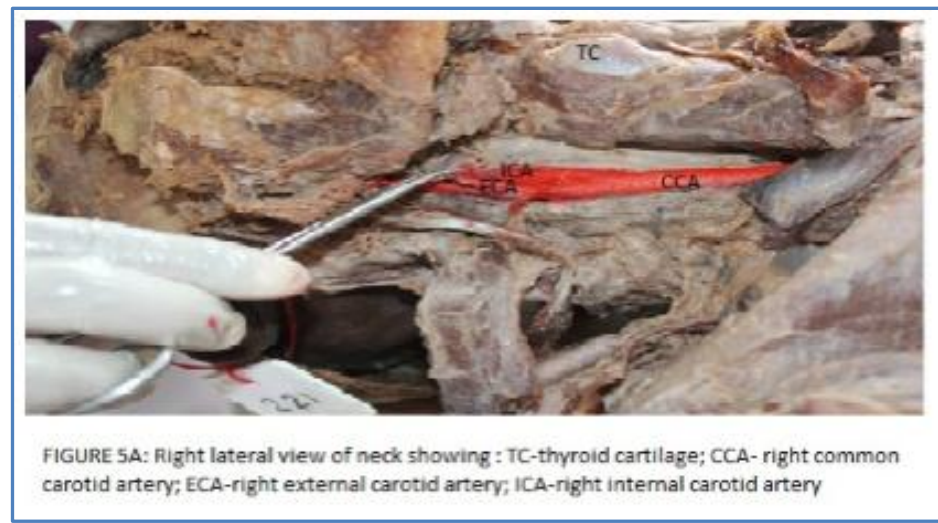




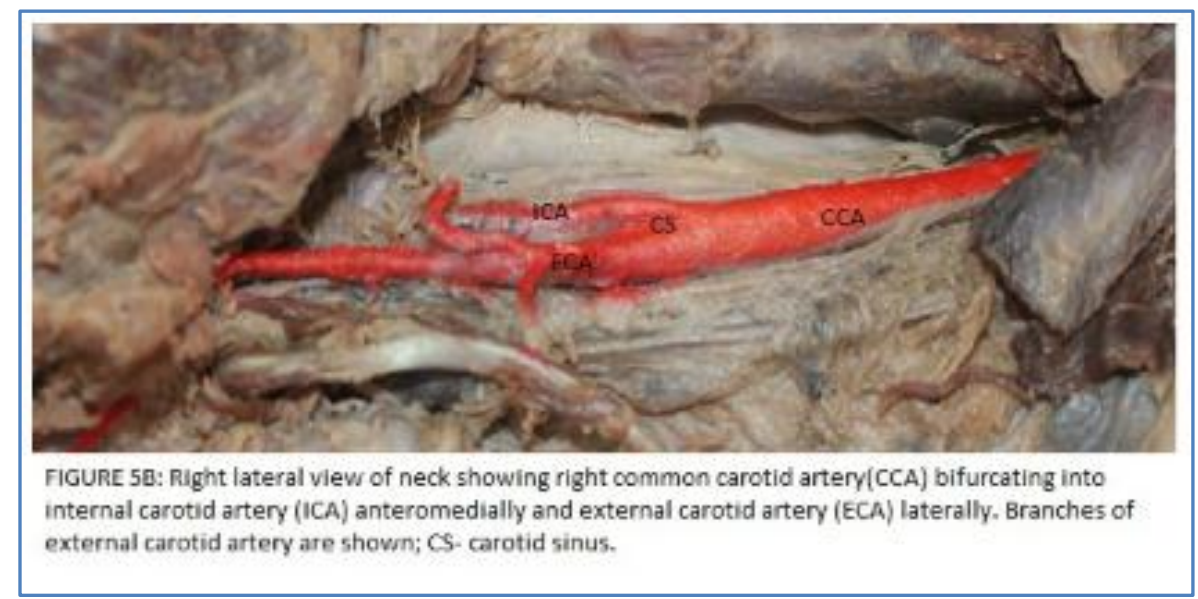

DISCUSSION: Arterial variations are not uncommon. Arterial variations were noted for the first time by Von Haller in 1813. The adult pattern of arteries develops from the axial trunk which extends from the axilla to the fingers and represents the axillary, brachial and interosseous arteries. The different arteries arise via sprouting angiogenesis (Singer, 1933).

The anomalous blood vessels may be due to:[1]

I. The choice of unusual paths in the primitive vascular plexuses.

II. The presence of vessels that are normally obliterated.

III. The disappearance of vessels that are normally retained.

IV. Incomplete development.

V. Fusion and absorption of the parts which are usually distinct (Dorros\& Lewin, 1986).

Unilateral arterial variations (24.45\%) in the upper limb are more common than bilateral variations (6.32\%) -McCoramack et al. Sprouting of aberrant blood vessels was proposed as reason for arterial variations (Singer, 1933; Lippert\& Pabst, 1985; O’Rahilly\& Muller, 1992).

The new theory proposed is, arterial pattern of upper limb develops from an initial capillary plexus by a proximal to distal differentiation, due to maintenance, enlargement and differentiation of certain capillary vessels and regression of other.[2]

Hence persistence, enlargement and differentiation of capillaries forming the initial capillary plexus, which would normally remain in a capillary state or even regress gives rise to arterial variations. The incidence of variations of superficial brachioulnar artery is $4.7 \% .{ }^{[2]}$

Variations in the branching pattern of Axillary artery noted by previous workers are:

In a report by Ravindra s. $s$ et al, the second part of the axillary artery gave rise to a common trunk from which subscapular and lateral thoracic arteries branched.[3]

Samta et al reported that the third part of axillary artery gave rise to a common trunk, which branched into subscapular artery, profunda brachii and circumflex humeral arteries, and also Alar branches arose from the second part of axillary artery.[4]

Saralaya $\mathrm{V}$ et al reported that there was a unilateral variation in the axillary artery, where, from the first part of axillary artery two branches were given. One is the superior thoracic artery and the other is a large branch which is termed as common subscapular trunk from which circumflex scapular artery, anterior and posterior circumflex humeral arteries, profunda brachii artery, ulnar 
collateral artery and thoracodorsal artery branched. The $2^{\text {nd }}$ and $3^{\text {rd }}$ part of the axillary artery did not give any branches.[5]

Bilateral common trunk of posterior cirumflex humeral and subscapular artery from the third part of axilla is noted in 3. 8\% of cases (Saeed et al; 2002).

Variations in the external carotid artery noted by previous workers are:

Handa et al mentioned that the first description of the lateral position of the External Carotid Artery was reported by an anatomist Hyrtl in 1841.[6] He described that medial or lateral External Carotid Artery migration during embryogenesis may be responsible for this anatomical variation.

According to Prendes et al, an anatomic variant for the position of the external carotid artery (ECA) at the carotid bifurcation was noted in 5.3 percent of patients studied by Doppler ultrasound and contrast angiography. The External Carotid Artery was lateral to and posterior to the internal carotid artery (ICA).[7]

According to Bussaka et al, lateral position of the external carotid artery was seen in 17 cases (4. 3\%), of which 13 cases were on the right side and 4 cases on the left side.[8]

At the origin, the internal carotid artery lies lateral as well as dorsal to external carotid artery. This can explain embryologically since the external carotid artery arises mainly from the ventral aorta and internal carotid artery arises mainly from the dorsal aorta (Datta. A. K; 2005).[9]

Variant posterolateral position of External carotid artery may be of particular interest to surgeons, cardiologist, radiologist and anatomists. Such variations must be given utmost importance before planning for any neck surgeries to avoid post-operative complications.

\section{In present Case:}

- Bilateral superficial brachioulnar artery is present, which is less common when compared to unilateral variation.

- Common trunk of subscapular and circumflex humeral artery, which further divides into anterior and posterior cirumflex humeral arteries are rarely reported in the literatures.

- The presence of unilateral posterolateral external carotid artery on the right side carries utmost clinical significance.

- Concomitant presence of this set of variations presented in this case is rarely cited in the literatures.

\section{CONCLUSION:}

- A good knowledge of the variations of the arterial pattern is must for a good treatment outcome especially in the fields like vascular surgery, reconstructive surgery, arterial cannulation, to avoid surgical complications etc.

- Radial artery is used for harvesting purpose in Coronary artery bypass graft procedures.

- Radial forearm flaps are used for cosmetic surgery, post burns, contractures of neck, nasal reconstruction etc.

- In renal failure patients, arterio- venous fistula is done for hemodialysis.

- Forearm arteries are also used for angioplasty purposes, for catheterization etc.

- Hence such variations should be kept in mind and should be given importance to avoid unnecessary surgical complications. 


\section{REFERENCES:}

1. Bidarkotimath, s.; Avadhani, r. \& Arunachalam, k. Primary pattern of arteries of upper limb with relevance to their variations. Int. J. Morphol., 29 (4): 1422-1428, (2011).

2. Rodriguez-Niedenfuhr: burton. g. 1 et al; Development of the arterial pattern in the upper limb of staged human embryos: normal development and anatomic variations; J. Anat. (2001) 199, pp. 407417.

3. Ravindra S. S; Mohandass K. G; variation in the axillary artery: a case report; J. case reports in vascular medicine; (2012).

4. Samta gaur;, S K. Katariya; H Vaishnani; I N Wani; K V Bondre; G V Shah; A Cadaveric Study of Branching Pattern of the Axillary Artery; Int. J. Biol Med Res. (2012); 3 (1): 1388-1391.

5. Vasudha Saralaya; Theresa Joy; Sampath Madhyastha; Rajanigandha Vadgaonkar \& Shruti Saralaya; Abnormal Branching of the Axillary Artery: Sub scapular Common Trunk. A Case Report; Int. J. Morphol., 26 (4): 963-966, (2008).

6. Handa J, Matsuda M, Handa H (1972). Lateral position of the external carotid artery. Report of a case. Radiology: 102: 361 - 2.

7. Prendes JL, McKinney WM, Buonanno FS, Jones AM (1980). Anatomic variations of the carotid bifurcation affecting Doppler scan interpretation. J. clin Ultrasound. 8: 147 - 150.

8. Bussaka H, Sato N, Oguni T, KorogiM, Yamashita Y, Takahashi M (1990). Lateralposition of ECA. Rhinshohoshasen 35: 1061 - 3.

9. A K. Datta (2005), Essential of human anatomy Head \&Neck. Calcutta (3rd edition) Current books international: pg -117 .

\section{AUTHORS: \\ 1. T. L. Anbumani \\ 2. A. Thamarai Selvi \\ 3. S. Anthony Ammal}

\section{PARTICULARS OF CONTRIBUTORS:}

1. Professor \& HOD, Department of Anatomy, Karpaga Vinayaga Institute of Medical Sciences.

2. Post Graduate, Department of Anatomy, Karpaga Vinayaga Institute of Medical Sciences.

\section{FINANCIAL OR OTHER} COMPETING INTERESTS: None
3. Post Graduate, Department of Anatomy, Karpaga Vinayaga Institute of Medical Sciences.

\section{NAME ADDRESS EMAIL ID OF THE} CORRESPONDING AUTHOR:

Dr. T. L. Anbumani, Professor \& HOD,

Department of Anatomy, Karpaga Vinayaga Institute of Medical Sciences, Maduranthagam.

E-mail: anbumanitl@gmail.com

Date of Submission: 18/02/2015.

Date of Peer Review: 19/02/2015.

Date of Acceptance: 27/02/2015.

Date of Publishing: 12/03/2015. 